\title{
ADDICTION TO MORPHIA AND ALLIED DRUGS SOME RECENT DEVELOPMENTS
}

\author{
By A. Spencer Paterson, M.D., M.R.C.P., Dipl.Psych. \\ Consultant Psychiatrist and Lecturer in the Medical School, West London Hospital \\ Consultant Psychiatrist, Stoke Mandeville and the French Hospitals
}

CAlthough addiction to opiates is not such a serious problem in Great Britain as in some other countries, it remains a constant potential danger to the community which only the vigilance of the police and careful prophylactic measures on the part of the medical profession prevent from becoming a realify. The problem has recently become acute in New York, where traffickers are said to be largely responsible for a violent crime wave at the present time (Sunday Times, August $15,1954)$. It is said that 6,500 youths are addicted to heroin and cocaine, while thousands of others smoke ' reefers.' In some districts one child in ten is an addict. As some youths spend $f 35$ a week on drugs it is not difficult to understand why many take to a life of crime. The police arrested 14 members of a ring which sells $£ 870,000$ worth of heroin every year.

The fact that the opiate problem is still alive in many countries has stimulated research in recent years, which has resulted in such discoveries as an efficient antidote to the opiate group and the synthesis of morphine by Gates and Tschudi (1952) (a discovery of some theoretical interest) and in a better understanding of the physiology of addiction.

In Great Britain and Northern Ireland during the last ten years there has been a decrease in the consumption of morphine and allied drugs but a marked increase in the consumption of Indian hemp. While in 1945 there were 49 prosecutions relating to the opiates, there were only two for Indian hemp, but in $195^{1}$ there were only nine for the opium group and 71 for Indian hemp, mostly in the form of 'reefer' cigarettes (Lyle, 1953).

\section{Pharmacology of the Opiates}

Effect of a single dose. This subject has been fully discussed in a recent review (Wikler, I953). A single dose of $30 \mathrm{mg}$. of morphine causes in a typical case meiosis, decrease in rate and depth of respiration, fall in body temperature, periphera vasodilatation, spasm of smooth muscle especially of the intestines, inhibition of diuresis, a passing rise os of blood pressure and pulse rate followed rapidly $N$ by the opposite; relief from pain and blunting of 을 appetite; and libido is diminished. It requires a $\rightarrow$ distinctly larger dose to produce the typical $\underset{\mathbb{D}}{\nabla}$ euphoria. It is therefore advisable in therapy to keep the dose under the threshold for euphoria to 3 diminish the danger of addiction. The greates degree of euphoria is achieved by intravenous ing jection. I have seen a patient with scars frota putting morphia powder into a vein. The maxe mum effects appear about 20 to 30 minutes after intravenous injection and 60 to 90 minutes by the subcutaneous route. It is important to remember that the effect lasts for about six hours, so therapeutic injections should not be more frequent.

Tolerance. If the drug is administered regularly $\overrightarrow{\vec{F}}$ tolerance develops, but at different rates for different symptoms. The same dosage fails in time to reproduce the analgesic euphoric and respiratory-depressant actions, whereas the effects on the pupil and on intestinal muscle are not affected.

Addiction.' The depressant effects mentioned above are followed by a rebound, but whether this 8 depends on a dual action of the drug or on a re- 3 action of the cell has not yet been decided. When 은 the next injection is almost due, effects which are $>$ mostly the opposite of those previously mentioned occur-yawning, lachrymation, rhinorrhoea, mydriasis, sweating and piloerection. There are also $\%$ subjective symptoms such as dysphoria, restless- $N$ ness and a craving for the drug. The onset of $\mathbb{E}$ addiction occurs because the injections become 0 more frequent and the doses higher as the victim tries to avoid the unpleasant pre-injection symptoms.

Acute withdrawal symptoms. Where an addict is 0 taking several grains a day the symptoms which 
occur on sudden withdrawal can be so severe as to cause death in debilitated subjects. Wikler divides them into non-purposive (somatic) and purposive (psychological) symptoms. The above pre-injection symptoms become very acute in 12 to 18 hours to which are added fever with increased rate of pulse and respiration, nausea, vomiting, diarrhoea, twitches and severe painful spasm of muscles, particularly in the legs, with tremors and a feeling of mental dullness. The peak is reached in 48 to 72 hours and symptoms gradually recede in the next 14 days. The patient's purposive behaviour depends on his character and environment. If he is told beforehand that the withdrawal symptoms are bearable, and if he has a strong character he will bear up. Others may have heard of deaths occurring and will exaggerate their symptoms in the hope that the medical attendant will continue the drug. Where the opiate is gradually cut down over a period of 7 to 14 days the great fear is for the period following the final injection.

Experiments on animals show that restlessness with stereotyped movements of circling and rooting, tremors and flexor spasms occur at the time of the expected injection, even when the cortex is removed. If a patient is leucotomized just after withdrawal symptoms, the purposive symptoms (craving) are greatly reduced. In general the E.E.G. shows slower rhythms during addiction but there is generally a slow return to normal during withdrawal.

Types of addict. In this country these may be divided into three classes: (I) Iatrogenic, where the patient has been given opiates for chronic or recurrent pain. (2) Unstable tense individuals who have access to opiates (physicians, nurses, pharmacists, veterinary surgeons, etc.). (3) Those in the entertainment world, whether artistes or pleasure seekers who are likely to encounter traffickers.

(I) Iatrogenic addicts. Morphine is essential in cases of severe pain as in renal- or gallstone-colic, tabetic crises, etc. However, the physician should always be alive to the possibility of addiction eventually occurring. He alone should give the drug or else one particular nurse. If the drug can reasonably be given by mouth or by suppository the syringe should be avoided. Great harm has been done by the suggestion in the past that some of the newer opiates are not habit forming, such as pethidine or physeptone.

The World Health Organization now recommends that every country should forbid the use of heroin absolutely because addiction to it is the most difficult to cure. It has no therapeutic value which is not possessed by morphine. Opiates should not be given for conditions other than pain, especially if the patient is an unbalanced individual and thus likely to become an addict.

It may be remarked that there are in every country a number of physicians who are themselves addicts, and who, by prescribing opiates freely cause some of their own patients to become victims.

Case history. Mrs. A.B., aged 53, was first seen by me in January 1952 . Fourteen years previously she had had an operation for an acute abscess in the pelvis. She also had had a hysterectomy. Later she had complained of intermittent pain, partly over the bladder and partly in the anal region. She was very tense and stated that she could not sit for long without intolerable pain. A sympathectomy had been carried out. She had been given omnopon by injection and this had gradually been increased till she was having $6 \mathrm{gr}$. a day.

On the psychological side she had always been of inferior intelligence. She was married to a surgeon and bore him two children. She was frequently unfaithful and there was later a divorce.

The psychiatrist who referred her described her as a completely hopeless case with poor personality and ideas of persecution directed ( $I$ ) against her husband, (2) all doctors who had ever attended her and (3) any nurse in charge of her.

The patient was taken off omnopon completely over a period of five days. As she was depressed and paranoid as well, the withdrawal period was masked by her receiving concentrated electroshock (one a day for ten days). In the next six weeks she went over the story of her life. She put on weight. She enjoyed going to the theatre with a nurse and never complained of any perineal pain throughout the performance. She did, however, notice where there were chemists' shops and doctors' plates, wondering whether she could simulate extreme pain. She accepted the psychogenic origin of her pain. After two months she returned home to a distant part of the country with a nurse. At a later date, however, she persuaded a physician once more to start on omnopon by injection.

It would appear, therefore, that many practitioners still prescribe these drugs too readily.

(2) Morphinism as an occupational hazard. One of the most celebrated of drug addicts was William Stewart Halsted, 1852-1922, one of the founders of the Johns Hopkins Hospital (Bell, 1952). Koller discovered the anaesthetic properties of cocaine in 1882 and Halsted and his two assistants experimented on themselves, eventually describing the advantages of ' regional anaesthesia,' among other things. The two assistants met with tragic deaths through addiction, but Halsted, with the help of his colleague Welch, who sent him to Ward Island for a year, and by his own immense will power finally 
won through to health and to great achievements in surgery.

One medical case that came under my care was that of a professor, aged 70 , from overseas. He had been a distinguished research worker as well as a brilliant athlete when he was younger. He was accustomed to take 6 . gr. of morphia a day but his efficiency was unimpaired. As he co-operated well, he was taken off the drug in the course of five days with $\mathrm{I} / 60 \mathrm{gr}$. atropine and $5 \mathrm{dr}$. of paraldehyde and $18 \mathrm{gr}$. amytal per day. He suffered mostly from restlessness and a spasm of the muscles of the legs. He developed severe gout. After the cure he became overactive and even hypomanic and set out for extensive travel abroad. He remained well but overactive till his death two years later.

(3) The irresponsible psychopath. A.B.C., aged 38 , had been a ne'er do well. His father had a successful business but the patient did not show the necessary perseverance to assist him. His mother drank gin to excess and smoked 50 cigarettes a day. As a young man he had a craving for drugs and would buy benzedrine inhalers and boil the impregnated rag and drink the water which caused pleasant hallucinations and contentment. He later started a radio business that failed. He then went into the Merchant Navy and encountered men smuggling cocaine. $\mathrm{He}$ took some of this for a time and also tried ' reefers.' As often happens the smoking of "reefers' led on to his injecting himself with heroin and he was eventually taking $5 \frac{1}{4}$ gr. a day. A doctor had him registered and obligingly supplied the drug. The patient was arrested at this time for having packets of 'reefers' in his possession which he had obtained from traffickers, but he was acquitted for lack of evidence. The shock of this made him anxious to be cured and he reduced his intake to $3 \mathrm{gr}$. a day. He refused to enter a hospital where he would be asked to stay for three months but he went into a general hospital and the dose was cut to zero in five days. $\mathrm{He}$ intends to go to South Africa to drive a lorry. The patient is almost certain to relapse within a few months.

The following gives some account of the activities of an Asiatic who peddled drugs stolen by accomplices from a London firm of chemists. A young girl giving evidence stated: 'He sold me a tube of tablets of heroin for 30 . but I was soon paying him $£ 40$ a week. Eventually he took my pencil and watch as well. About midnight on April to he came to my house and said: "This will make your mouth water" and opened a case with hundreds of bottles of morphine, cocaine, phenobarbitone, etc. He gave me some cocaine in a piece of paper and said: "Show this to your friends and see if they want any." He said the drugs were worth $f_{1}, 300$ but he would let me $\mathbb{\otimes}$ have them for $£ 500$.'

In July $195^{\circ}$ about 80 police officers raided a dance hall in Soho. The men were mainly coloured and the girls white. Eight coloured men were arrested fòr having Indian hemp in their possession. Several of these men were very excited and hysterical and one bit two policemen and a civilian. In court he solemnly stated that $\%$ they had bitten him first. As these men were all $\vec{O}$ quiet and docile when seen on subsequent occasions, it was thought that they were suffering from the effects of hemp smoking at the time of the raid. During the search 20 packets of hemp and $\mathscr{C}$ several knives were found on the floor.

The reasons for smoking hemp were given as follows: Artist, 39, 'Inspiration'; girl, 25, ç 'Couldn't care less'; coloured man, 23, 'No O shame'; man, 20, 'Cheaper than drink'; N coloured man, 25, 'Can fight for myself better'; $N$ musician, 27, ' Can capture the notes better.' The smoking of 'reefers' is, as already stated, a $\vec{r}$ common intermediate step to starting the heroin $\mathbb{D}$ or morphine habit.

Medico-legal aspects. Under the Dangerow Drugs Act, 1920 , every medical practitioner must $\stackrel{\mathbb{}}{-}$ keep drugs of this category under lock and keक. $\overrightarrow{0}$ $\mathrm{He}$ must give a written prescription for only limited amount. If he is prescribing the drug for an addict, he must inform the Home Office. Probably opinion in favour of compulsory treatment is more prevalent among psychiatrists now than ever before and the question is likely to be $\frac{\mathrm{D}}{\mathbb{D}}$ discussed in Parliament in the next year or two. $\varrho$ Willcox was in favour of it but the opinion of the $\overrightarrow{\vec{O}}$ medico-legal Society of London in 1923 was ' emphatic' against such powers. It certainly does seem remarkable that an addict should have the? best chance of cure only if he becomes a criminalo and goes to prison for a long stretch. At present:it is possible for an addict to ask to enter a clinic 3 for a specified period and to be kept there even if he changes his mind. In practice, however, it becomes impossible for the institution to keep the patient if he does change his mind.

$N$-allylnormorphine.* This is a remarkable anti- $\frac{D}{0}$ dote to morphine and also to its synthetic substitutes (Unna, 1943). It appears to act at the same sites as morphine but displaces it. Its chief uses are (I) to help in rapidly diagnosing the degree of addiction. When an addict is injected with it ${ }^{\omega}$ the degree of severity of the symptoms of with drawal from morphine indicates the degree of

* In Great Britain it is marketed under the name of lethidrone (B. W. \& Co.). 
dependence, a fact which otherwise might take a very long time to discover. (2) Old patients who are given an injection of morphine may show an idiosyncrasy to the drug and respiration may be depressed to a dangerous degree. This drug will bring about immediate relief. (3) In obstetrics if the mother is injected with morphia, the foetal respiration may be dangerously depressed and an injection of the antidote may save its life. (4) In some parts of the world it is estimated that as many as 50 per cent. of addicts attempt suicide by an overdose in a final orgy. Such cases again can be saved. The antidote is not, however, used for the treatment of the ordinary addict.

Institutional care. It must be emphasized that the prognosis is extremely grave in nearly all cases of addiction and it is, therefore, essential that the patient be sent to an institution where the physician specializes in such cases. It is advisable that the patient should be under the same physician throughout the treatment. Care is taken by such devices as changing the patient's room while he is in a bath to make sure that he has no access to drugs hidden away. As a rule the drug is reduced to a dose just above that which causes withdrawal symptoms and then lessened by one-seventh each day so that by the end of a week the patient is off the drug. The pain of withdrawal is mitigated by administration of other drugs such as hyoscine, paraldehyde, sodium amytal or other barbiturates care being taken to see that respiration is not too much depressed through combination of opiate and barbiturates. Sometimes electroshock has been given to patients in good physical condition to tide over the withdrawal period. A useful procedure is to give the patient 50 to $100 \mathrm{cc}$. of 5 per cent. glucose I.V. if the heart is sufficiently strong. If there is much vomiting, normal saline can be added to the injection. Glucose drinks should be given ad lib. Very high doses of the vitamin $\mathrm{B}$ complex may also be given with great benefit I.V. as parentrovite (Vitamins Ltd.). The craving, however, is likely to continue in lesserdegree but with exacerbations for some years. It does become less severe after nine months. This period is considered the optimum for institutional care.

Prognosis. Junless the utmost precautions are taken the chances of abstinence lasting five years may be as low as 2 per cent. (Wolff, 1945). Those who are treated by compulsion for nine months show better results than voluntary patients: Factors in good prognosis are comparatively short duration of addiction; cases where the original administration was for relief of pain; good personality and high intelligence; interesting work; addiction to only one drug and that not heroin; a cycloid rather than an epileptoid temperament; rapid withdrawal (in one week); where the drug was not taken by injection. The addition of psychotherapy and the ultimate attainment of good physical health also count. A change to an environment where the drug is not easily available and supervision at intervals over a period of years also help. Under such conditions the percentage of recovery may be over 50 per cent. The prognosis is therefore by no means hopeless if every care is taken to give the patient the best available. treatment.

\section{BIBLIOGRAPHY}

BELL, W. R (I952) 'William Stewart Halsted, Cocaine Pionee and Addict,' Brit. F. Addiction, 11, I, 53.

GATES, M. and TSCHUDI, G. (1952), f. Amer. Chem. Soc., 74, 1 rog.

LYLE, G. (1953), 'Dangerous Drugs Traffic in London,' Brit. $\mathcal{F}$. Addiction, 50, I, 47.

UNNA, K. (1943), F. Pharm. Exper. Ther. 79, 27.

WIKLER, A. (1953), 'Neurophysiological Aspects of the Opiate and Barbiturate Abstinence Syndromes,' Research Pub. Ass. Res. Nerv. Ment. Dis., 32, 269.

WOLFF, P. O. (t945), 'The 'Treatment of Drug Addicts,' Bulletin, of W.H.O. XII, 4 .

WOLFF, P. O. (1953), 'The Activities of W.H.O. in Drug Addiction,' Brit. $\mathcal{F}$. Addiction, 50, $1,12$.

\section{RUTHIN CASTLE, NORTH WALES}

A Clinic for the diagnosis and treatment of Internal Diseases (except Mental or Infectious Diseases). The Clinic is provided with a staff of doctors, technicians and nurses.

The surroundings are beautiful. The climate is mild. There is central heating throughout. The annual rainfall is $\mathbf{3 0 . 5}$ inches, that is, less than the average for England.

The Fees are inclusive and vary according to the room occupied.

For particulars apply to THE SECRETARY, Ruthin Castle, North Wales. 